\title{
APLICAÇ̃̃O DA TEORIA DO CUIDADO TRANSPESSOAL EM PACIENTES PARAPLÉGICOS HOSPITALIZADOS: RELATO DE EXPERIÊNCIA*
}

\author{
APLICACIÓN DE LA TEORÍA DEL CUIDADO TRANSPERSONAL EN PACIENTES \\ PARAPLÉIICOSHOSPITALIZADOS: RELATO DE EXPERIENCIA
}

\author{
APPLICATION OF TRANSPERSOAL CARING THEORY IN \\ PARAPLEGIC IN PATIENT: REPORT OF AN EXPERIENCE \\ ZUILA MARIA DE FIGUEIREDO CARVALH O** \\ MARTA MARIA COELHO DAMASCEN O***
}

\begin{abstract}
RESUMO
Relato de experiência so bre o processo de cuidar e de ensinar a cuidar de pessoas paraplégicas utilizando a teoria do cuidado transpessoal de Jean Watson. É um estudo descritivo, que envolveu seis pacientes, duas docentes do D epartamento de Enfermagem da Universidade Federal do Ceará (UFC) e quarenta alunos matriculados na disciplina Processo de Cuidar II. A coleta dos dados aconteceu no período de abril de 2000 a abril de 2001, mediante entrevistas semi-estruturada que envolveu questões relativas à perda e ao cuidado. Para a aplicação da teoria, foram seguidas as etapas do processo de enfermagem preconizadas por Alfaro-LeFevre (2000), ten do os pacientes, docentes e alunos, sido considerados parcei ros na relação ser cuidado e ensinar/aprender a cuidar. Os pacientes expressam que esta nova estratégia de cuidado gera satisfação e incentivou a realização de práticas inovadoras, tais como: cuidados alternativos do tipo toque e abraços, contato visual e atitude calma. Os alunos, se deram conta da importância do planejamento do cuidado com a pessoa paraplégica, para, assim, prestarem cuidados mais humanísticos e de melhor qualidade. Foi um momento de descobrimento, de exercício da intersubjetividade, pois, na medida em que interagíamos com os pacientes, aprendíamos e refletíamos sobre suas maneiras de viver, ser e agir e, juntos, procurávamos compreender o significado do cuidado ao paraplégico através de diálogos. Assim, aplicar o modelo de cuidado transpessoal em paraplégicos hospitalizados, foi uma maneira de estender a teoria à prática e representou uma oportunidade de crescimento e autonomia da enfermagem no cenário hospitalar.
\end{abstract}

Unitermos: Paraplégicos, teoria do cuidado transpessoal, enfermagem.

\section{RESUMEN}

Relato de experiencia sobre el proceso de cuidar y de enseñar a cuidar de personas parapléjicas, utilizando la teoría del cuidado transpersonal de Jean Watson. Es un estudio descriptivo que incluyó 6 pacientes, 2 docentes del Departamento deEnfermería de la Universidad Federal del Ceará (UFC) y 40 alumnosinscritosen la asignatura Proceso de Cuidar II. La recolección de los datos fue realizada en el período de abril de 2000 hasta abril de 2001, mediante entrevistas semi-estructuradas que incluyeron preguntas relativas a la incapacidad y al cuidado. Para la aplicación de esa teoría se siguieron las etapas del proceso de enfermería preconizadas por Alvaro-Le

\footnotetext{
*Parte da Tese de Doutorado "O cuidado com a pessoa paraplégica hospitalizada : estudo à luz da Teoria de ean Watson, apresentada eaprovada pelo Programa dePós-Graduação em Enfermagem do Departamento deEnfermagem da Faculdade deFarmácia, O dontologia e Enfermagem da Universidade Federal do Ceará. A tese contou com o apoi o financeiro da fundação Cearense de Desenvolvimento Cientifico e Tecnológico - FU NCAP e do Conselho Nacional de Desenvolvimento Científico eTecnológico (CNPq).

**Enfermeira. D outora em Enfermagem. Docente do Departamento de Enfermagem da Faculdade de Farmácia, Odontologia e Enfermagem da Universidade Federal do Ceará. Bolsista da FU N CAP. Fortaleza-Ceará-Brasil.

***Enfermeira. Doutora em Enfermagem. Docente do Programa de Pós-Graduação em Enfermagem do Departamento de Enfermagem da Faculdade de Farmácia, Odontologia e Enfermagem da Universidade Federal do Ceará. Pesquisadora do CN Pq. Endereço: Av. Sem. Virgílio Távora, 1900/401;Aldeota; CEP: 601670251; Fortaleza-Ceará-Brasil.E-mail:marta@ufc.br
} 
Fevre (2000), considerando a los pacientes, docentes y al umnos compañerosen la relación "ser cuidado, enseñar y aprender a cuidar". Los pacientes expresan que esta nueva estrategia de cuidado desarrolla satisfación, estimulando la realización de prácticas innovadoras, tales como cuidados alternativos del tipo: caricias en los abrazos, contacto visual y actitud tranquila para entregar cuidados más humanos y de mejor calidad. Fue un momento de descubrimiento, de ejercicio de la inter-subjetividad, pues, mientras compartíamos con los pacientes, aprendíamos y reflexionábamos al respecto de sus modos de vivir, ser y actuar, procuramos la comprensión del significado del cuidado a parapléjicos hospitalizados a través de los diálogos. Así, probamos el Modelo de Cuidado Transpersonal en parapléjicos hospitalizados, verificando una manera de extender la teoría a la práctica, representando una oportunidad de crecimiento, autonomía de la enfermería en el ambiente hospitalario.

Palabras claves: Parapléjicos, teoría del cuidado transpersonal, enfermería.

\begin{abstract}
A report of the experience on the process of taking care and of teaching to take care of paraplegic people using the transpersonal caring theory of Jean Watson's. It is a descriptive study, that involved six patients, two professors of Nursing D epartment of theFederal University of Ceará (UFC) and forty students registered in the discipline Process of Taking Carell. The collection of the data was carried out between April, 2000 and April, 2001, by means of semi-structured interviews that involved subjects related with inability and caring. For the application of the theory, nursing process stages were followed acording to Alfaro LeFevre (2000). The patients, professors and students, were considered partners in the relationship of taking care and teaching/learning to take care. The patients express that this new caring strategy gener ates satisfaction motivating the accomplishment of innovative practices, such as: alternative cares of thetype play and hugs, visual contact and quiet attitude. The students were given bill of the importance of the planning of taking care of the paraplegic persons, for which, they offer more humanistic caring and of better quality. It was a moment of discovery, with the patients, and we contemplated on their styles of living, to be and to act and, together, wetried to understand the meaning of taking care of the paraplegic through our dialogues. Thus, to apply the model of transpersonal caring in paraplegic inpatients, it was a way to extend the theory to the practice which represented a growth opportunity and autonomy of nursing in the hospital environment.
\end{abstract}

Keywords: Paraplegic, transpersonal caring theory, nursing.

Recepcionado: 21.06.2003. Aceptado: 03.12.2003.

\section{INTRODUÇÃO}

$\mathrm{Na}$ experiência como docentes da disciplina Metodologia da Assistência de Enfermagem em cursos de especialização, temos ouvido as enfermeiras alegarem que as teorias, assim como os esquemas conceituais, são inexeqüíveis na prática. Assim sendo, poucas tentativas de aplicação têm sido realizadas, contribuindo cada vez mais para que o cuidar continue assistemático. A respeito desse assunto, percebemosquea deficiência no ensino de graduação e a incongruência entre o modelo funcionalista dos serviços de saúde e os princípios humanísticos das teorias de enferma- gem são, dentre outras, dificuldades encontradas para a aplicação dos modelos teóricos, na prática.

Tal realidadetem sido uma inquietação que nos faz perguntar: o que uma teoria representa no planejamento do cuidado? A utilização de teorias éuma alternativa para resolver a questão do cuidado de enfermagem?

Em seus estudos (Chinn e Kramer, 1995; Hickman, 2000; Carraro, 2001), defendem que o uso das teorias de enfermagem promove a identidadeprofissional poisforneceuma base firme na qual a enfermeira se apoia quando suas idéias são questionadas. Além disso, acrescentam que elas são úteisà prática, eque, 
diante da opção por uma ou outra teoria, é importante considerar sua adequação e aplicabilidade à situação em que será utilizada.

Contrariando a tendência vigente de não valorizar o uso de teorias de enfermagem, começamos a amadurecer a idéia de aplicar uma teoria numa determinada situação de prática, isto é, no cuidado a paraplégicos hospitalizados.

A fase de coleta de dados da nossa tese de doutorado, uma vez abrangendo entrevistas com aqueles clientes, forneceu rico material e com ele a oportunidade da aplicação da teoria do cuidado transpessoal de Jean Watson, referencial que apoiaria a análise dos dados.

Assim, decidimos enfrentar o desafio, envolvendo, no processo de cuidar, docentes de enfermagem, alunos de graduação em enfermagem e pacientes paraplégicos na forma de estreita parceria.

Watson (1999) sugere que sejam realizados estudos no sentido de aplicar sua teoria do cuidado transpessoal de modo a confirmar as bases do seu modelo de cuidar e, com isso, validá-lo. Inicialmente, cabe lembrar que o modelo é interacionista e que a sua prática acontece através das interações paciente/enfermeira. Com basenessa premissa, iniciamos uma nova maneira de cuidar e de ensinar os alunos de graduação, a cuidarem das pessoas paraplégicas. Como parceiras no cuidado mantivemos contato direto com os pacientes durante o período de hospitalização e também, após a alta hospitalar, em forma de visitas domiciliares, ligações telefônicas ee-mails.

A parceria no cuidado é uma experiência que se caracteriza pelo diálogo significativo entre pessoas, no qual cada uma sente a disponibilidade, a proximidade e a compreensão da outra. Inclui a capacidade de reconhecer nossa própria obrigação de atuar, isto é, intervir para ajudar aos outros a ajudarem a si mesmos, e, para que isto aconteça, é necessário que a enfermeira se reconheça como pessoa.

É, portanto, preciso considerar quena relação enfermeira/paciente estão presentes duas pessoas, com seus discursos, histórias devida, trajetórias e angústias. Ignorar esse aspecto significa perpetuar relaçõesalienadas descontextualizadas, de dependên cia e submissão. A parceria no cuidado de enfermagem, na experiência ora relatada, évista como um navio que irá transportar o paciente, com a ajuda do parceiro, através das águas inconstantes do sistema de cuidar da saúde e o mar áspero da paraplegia.

Nesse sentido, ao trabalhar com pessoas fragilizadas pela paraplegia e pelo sofrimento, é exigido da enfermeira exercitar a sua própria pessoa, quer compartilhando sentimentos, quer utilizando um enfoque intelectual direcionado aos problemas, o que requer que ela domine os fatos, os princípios e conceitos daquilo que ela pensa. Existe, ainda, a acessibilidade da experiência na parceria que se caracteriza pela capacidade de permitir quecoexistam problemas ou sentimentos opostos, sem buscar solução imediata para eles. 0 papel da enfermeira consisteem estruturar a parceria de tal modo que o paciente possa experimentar essa acessibilidade.

Compartilhando das concepções deWatson (1988), entendemos a parceria de cuidado como um processo interpessoal, no qual uma pessoa necessita de ajuda ea outra a fornece. $E$ o objetivo dessa ajuda é favorecer meios para que o paciente enfrente a situação da paraplegia, aprenda com a experiência e encontre o seu significado.

Diante do exposto, o estudo objetiva descrever a experiência da aplicação da teoría do cuidado transpessoal de Watson no cuidado a paraplégicos hospitalizados.

\section{A TRAJETÓRIA METODOLÓGICA}

Visando estabelecer a parceria, alguns momentos bem significativos aconteceram. Primeiramente, nos apresentávamos ao paciente efamiliar, falávamos do desejo de ajudá-lo e que para tal havia necessidade de que ele desejasseser ajudado. Ficava estabelecido que 
a parceria era uma forma de nos ajudarmose que a sinceridade entre nós era primordial. N ossos encontros aconteceram na enfermaria, quando da prestação de cuidados do tipo banho no chuveiro, transferências da cama para a cadeira de rodas e vice-versa, passeios em cadeira de rodas pelas dependências do hospital, banho de sol no jardim; tudo isso acompanhado de atitudes empáticas, de calor humano, permeado por brincadeiras e, algumas vezes, atépor atos de cantar. Com os diálogos entre nós, os alunos e pacientes internados, a proposta de implementação do cuidado em parceria foi definida.

Para a aplicação da teoria a amostra envolveu seis pacientes que estavam internados no Instituto Dr. J oséFrota, local izado em Fortaleza - Ceará - Brasil. Alguns critérios foram levados em consideração, dentreosquais destacam-se: 1) ser lesado medular por trauma com déficit motor do tipo paraplegia, e que já tenha sido informado da incapacidadepara andar. Segundo M achado (2000) tal fato leva a pessoa a procurar fazer um balanço, avaliando as implicações da perda sofrida e perscrutar alguma forma desubstituí-la; 2) ser do sexo masculino, visto que, Padula (1998) reporta que os homens constituem a maior demanda de lesados medulares, sendo cinco vezes mais acometidos queas mulheres pel o fato deestarem mais expostos aos acidentes eagressões; 3) estar orientado no tempo eno espaço.

A coleta de dados aconteceu mediante entrevista semi-estruturada que se realizou com base nas questões norteadoras: como você se sente por ser paraplégico? que cuidados você gostaria de receber da enfermeira? A opção por recurso metodológico fundamentou-se em Tobar eYalour (2001) que defendem que a entrevista pesquisa intensamente um tema particular permitindo um entendimento 0 mais completo e detalhado possível do tema abordado. As questões foram designadas como $A$ e $B$, respectivamente, tendo sido escolhidas por representarem o trabalho deautoria deWatson (1988) na área da perda e do cuidado, ou seja, centradas na significação do fenômeno perda e no significado de cuidado para as pessoas que a vivencia. Ambas foram utilizadas pela autora, ao testar a teoria num estudo de campo em Cundeelee, na Austrália O cidental, com uma tribo de aborígines.

As entrevistas foram agendadas de acordo com as disponibilidades dos entrevistados e das entrevistadoras. Procuramos manter um clima de cooperação, não assumindo postura de distanciamento ou dispersão do assunto que viesse fragmentar ou cessar o pensamento ou fala dos respondentes. Na medida do possível, buscamosambientes quenosgarantissem privacidade, conforto eliberdade, dentre os quais a praça de lazer do próprio hospital. O uso do gravador assegurou a fidedignidade da reprodução dos discursos que foram transcritoselidos exaustivamente o que possibilitou a categorização e seu respectivo processo de análise.

A partir das respostas das questões $A$ e $B$, foram determinados os passos da operacionalização do modelo que se basearam nasetapas da metodologia da assistência de enfermagem, preconizadas por Alfaro-LeFevre (2000), visto que Watson não apresenta um modelo próprio que utilize as etapas do método científico. Entre elas inclui-se: o levantamento dos dados, a elaboração de diagnósticos deenfermagem, o planejamento dos cuidados transpessoais, a implementação e a avaliação/evolução. Essas fases são seqüenciais e interrelacionadas, integrando as funções intel ectuais do método de solução de problemas em um esforço para definir as ações de enfermagem na parceria.

O levantamento dos dadostevecomo propósito identificar problemas, preocupações, necessidades afetadas ou reações humanas do paciente, a partir das respostas às questões norteadoras enumeradas páginas atrás.

A elaboração dos diagnósticos de enfermagem foi apoiada na proposta de lyer et al. (1993) econstituiu-se deduasfases: na primeira, procedeu-se a análise e síntese dos dados levantados e, na outra, o estabelecimento do diagnóstico propriamentedito, constituído de 
categoria diagnóstica, fatores relacionados e características definidoras, conforme a taxonomia da North American Nursing Diagnosis Association - NANDA (2000).

Para a etapa relativa ao planejamento dos cuidados é importante ressaltar que foram considerados o estabelecimento de prioridades para os problemas identificados, os diagnósticos de enfermagem elaborados e a fixação de metas com base nos dez fatores de cuidados preconizados por Watson (1979; 1985). A partir desse conjunto de informações foram prescritos os cuidados a serem implementados na parceria.

No que toca à evolução/avaliação, sabe-se quea evolução éuma fase sempreem processo que determina o quanto as metas de cuidados foram alcançadas eo progresso do paciente. Assim, instituímosmedidas corretivas e revisamos o plano de cuidados, sempreque foi necessário. Para a avaliação, procedemos deforma semelhanteàs estudiosas Schoroeder e M aeve (1992) ao avaliarem a parceria realizada em um estudo no Centro de Cuidado do Projeto Denver, por ocasião da aplicação do modelo transpessoal deWatson. Os dados referentes a essa etapa foram obtidos mediante uma terceira pergunta (C) dirigida ao paciente: o que você tem a dizer sobre a parceria? Cabe destacar que, tanto os dados le vantados como os relativosa avaliação da parceria, estão apresentados na íntegra das respostas das questões A, B e C. Conforme preconiza a Resolução 196/96 (1997), foi solicitada aos participantes a assinatura do Termo de Consentimento Livre e Esclarecido.

A teoria foi aplicada entre abril de 2000 e abril de2001, eos encontros, em média dedez, aconteceram no período da manhã das 7h30 min às 11h30min.

\section{A APLICAÇÃO DA TEORIA}

Antes da aplicação propriamente dita, optamos por trazer um breve resumo dos dados de identificação eda situação sócio-econômica decada pacientecom nomes fictícios, para, em seguida, apresentarmos os passos da implementação do modelo:

PAULO, 48 anos, casado, pedreiro, católico não-praticante. É declasse média baixa, mora em casa própria com a esposa eum filho, tem o ensino fundamental completo. Internado em 18/03/2000, apresentando traumatismo raquimedular (TRM ) $T_{12}$ com paraplegiaflácida ocasionado por desabamento de parede. Submetido à artrodese de coluna torácica. Encontra-se hospitalizado há 52 dias.

\section{Levantamento dos dados}

"No momento eu estou bem, graças a Deus. Eu só creio na vida, que graças a Deus eu vou ficar bom, se Deusquiser eu ainda vou andar, essa féeu tenho em D eus. Sabe, àsvezes, dá uma tristeza muito grande. Eu pensava que depois da cirurgia tudo voltava ao normal... eu voltava a andar... estou muito triste por isso". (A)

"Tudo isso que elas já estão fazendo, banho, me virar na cama, colocar travesseiros nas pernas, atéuns saquinhos com água embaixo do pé elas colocam, essas coisas, elas tão cuidando o que sinto falta é que elas não têm tempo para conversar comigo, sabe as alunas quevão ser doutoras conversam com os doentes. Elas pegam os doentes botam na cadeira de roda evão passear, isso alegra a gente sabe, assim, a gente sente que alguém tá preocupado. Olha eu não estou redamando, porque mesmo assim, aqui no hospital tudo é muito bom. Sabe, eu queria que alguém falasse comigo como eu vou viver com minha mulher... (ficou encabulado). Sabe doutora essas coisas de homem e mulher têm mepreocupado, seria bom seas doutoras falassem disso com a gente". (B) 


\section{Diagnósticos de enfermagem}

- Alteração sensorial de percepção sinestésica relacionada à transmissão sensorial alterada, evidenciada pela ausência da sensibilidadenos M M II.

- Impotência relacionada ao estilo de vida de desamparo, evidenciada pelo relato verbal de não ter controle ou influência sobre a situação.

- Déficit de conhecimento sobre paraplegia relacionado à interpretação errônea de informação, evidenciado pelo relato verbal do problema.

- M obilidade física prejudicada, relacionada a prejuízo neuromuscular, evidenciada por paraplegia de mobilidade.

- Disfunção sexual, relacionada às estruturas da função corporal alteradas pela lesão medular, evidenciada pela ausência de ereção e verbalização da incapacidade sexual.

\section{Planejamento do cuidar/cuidado}

M etas - Atenção especial aos fatores decuidado

Fator 4. Relação de ajuda-confiança.

Fator 5. Expressão de sentimentos positivose negativos.

Fator 7. Ensino-aprendizagem transpessoal.

Fator 8. Ambiente de apoio, proteção e/ou de neutralização mental, física, sociocultural e espiritual.

Fator 9. Satisfação das necessidades humanas: eliminação vesical e intestinal; sexualidade, mobilização e socialização.

\section{Cuidados transpessoais}

- Oferecer suporte emocional através do diálogo e do aconselhamento, estimulando a confiança.

- Falar, individualmente, sobre o tipo de le são que ele apresenta e as repercussões na sua sexualidade.
- M anter diálogo aberto efranco sobreos sentimentos, deixando aflorar os medos, favorecendo um diálogo franco.

- Estimular a socialização através de contatos com os amigos.

- Reservar um tempo para deixá-lo expressar seus sentimentos.

- Estimular o uso de terapias para promover a saúde, incluindo massagens, toque, aconselhamento.

- Promover ambiente seguro e de apoio.

- Ensinar a reeducação vesical eintestinal.

- Implementar cuidados relativos a higiene, al imentação, eliminações, mobilidadefísica, e integridade cutâneo-mucosa.

- Ajudar a sentar na cadeira de rodas, ensinar os mecanismos com o corpo e a cadeira.

- Propiciar condições para que o paciente re conheça queaindaécapaz deum relacionamento sexual.

- Fazer orientação individual sobrenovastécnicas e maneiras de realizar a atividade sexual.

\section{Evolução}

No decorrer da parceria, mostrou-se mais alegre. A prendeu o autocateterismo intermitente, as técnicas de tran sferência da cama paraa cadei ra de rodas e as exercita com ajuda dos familiares. Apresenta dificuldades em aprender sobre paraplegia eoutros cuidados necessários à vida cotidiana. M ostrou interesse nas orientações relacionadas à sexualidade. Sente-se esclarecido e com vontade de recomeçar a vida cotidiana. Requer ajuda do acompanhantepara efetuar a mudança de decúbito e transferência da cama/cadeira e vice-versa.

\section{Avaliação}

"Eu gosto da maneira como vocêscuidam de mim, de como me ensinam e informam as coisas; eu preciso estar com pessoas que se preocupam comigo; vocês fa- 
zem as coisas na medida que são necessárias e me ajudam a tomar decisão. Eu gosto deter quando eu preciso, deal guém familiarizado com a paraplegia e comigo. Sabe, a sra. eas alunas que vão ser doutorasenfermeiras, conversam com os doentes, colocam a gente na cadeira de rodas, passeiam com a genteno jardim, isso alegra a gente. Sabe, assim a gente senteque alguém está preocupado comigo". (C)

No dia 05/05/2000 foi o último encontro com Paulo, ficando assim suspensa a implementação no plano do hospital, visto que ele receberia al ta hospitalar no dia seguinte. N este dia, revisamos os termos da parceria, foi reforçado 0 acordo de que ele poderia telefonar semprequesentissenecessidade. D espedimonoscom troca de abraços. Eletel efonava sempre que surgiam dúvidas ou mesmo quando se sentia muito só ou deprimido.

PED RO, 27 anos, solteiro, agricultor, católico não praticante. É de classe média, mora no interior do estado, em casa própria, com a mãe e três irmãos. Tem escolaridade equivalente ao ensino médio completo. Foi admitido em 27/03/2000, após queda de coqueiro. Apresenta TRM com paraplegia de mobilidade $\mathrm{T}_{12}{ }^{\prime}$ nível sensitivo $T_{9}$. Realizou artrodese de coluna torácica. Encontra-se hospitalizado há 45 dias. A parceria com o Pedro foi permeada de onze encontros, o primeiro dos quais aconteceu no dia 11/05/2000, pela manhã.

\section{Levantamento dos dados}

"Sinto-meassim um pouco tristené, que seja assim um pouco triste (pausa), na verdade muito triste para quem andava, fazia todos os movimentos éisso mesmo, éuma tristeza. Fazia todos os movimentose estou assim agora, numa cadeira de rodas. Me sinto tristonho, desejoso de retornar a minha vida anterior". (A)
"Gostaria que me seja ensinado os cuidados para eu dar continuidade do tratamento quando for para casa. Tenho interesseem aprender sobre a paraplegia e como andar de cadeira de rodas, para encarar a vida como paraplégico. Outros cuidados que eu gostaria de receber: orientaçõesque são necessáriasa pessoa usar em casa, como passar uma sonda, exerć́ciosfísicos. Gostaria muito também que a enfermei ra tivesse mais diálogo com a gente, conversasse mais com a gente, que elas estimulassem mais o paciente, desse um pouco mais deatenção. É isso queestá faltando. A gente sente falta porque, ge ralmente, elas visitam o leito só quando vai apresentar o trabalho para outra, só isso mesmo. A não ser assim, num caso de urgência, se o paciente passa mal é onde tem a presença delas, dasenfermeiras". (B)

\section{Diagnósticos de enfermagem}

- Sentimento depesar disfuncional relacionado à paraplegia evidenciado por expressão de tristeza quanto à perda.

- Distúrbio da imagem corporal relacionado ao trauma (paraplegia), evidenciado pelo relato verbal de sentimentos que refletem uma visão alterada do próprio corpo na aparência.

- Déficit de conhecimento sobre paraplegia relacionado à falta de informação, evidenciado pela verbalização do problema.

- Mobilidadefísica prejudicada relacionada a prejuízo neuromuscular, evidenciada por paraplegia de mobilidade.

\section{Planejamento do cuidar/cuidado}

M etas - Atenção especial aos fatores decuidado

Fator 2. Féesperança.

Fator 7. Ensino-aprendizagem transpessoal.

Fator 9. Assistência àsnecessidades humanas: mobilização. 


\section{Cuidados transpessoais}

- M anter diálogo aberto efranco sobre os sentimentos, deixar aflorar o choro, oferecer 0 ombro para ele chorar.

- Ficar ao seu lado, segurar a mão, incentivar a locomoção, indo para a pracinha do hospital.

- Estimular a participação no autocuidado (banhar-se, higiene oral, barbear-se).

- Oferecer conforto pela participação.

- Compartilhar a dor.

- Ajudar a estabelecer metas de autocrescimento.

- Discutir estratégias para a vida cotidiana, estabelecer metas a curto, médio e longo prazo.

- Ensinar técnicas de transferência da cama para a cadeira e vice- versa.

- Orientar quanto à utilização de coxins ealmofadas deágua para o posicionamento no leito.

- Ensinar o autocateterismo, manobras de Vasalva e de Credé para favorecer a micção.

- Ensinar massagens abdominais.

\section{Evolução}

0 paciente sente-se ajudado e apoiado; verbaliza seus sentimentos e discute as melhores opções para continuidade da sua vida. Diz encontrar em Deus um refúgio para o seu problema. Aprendeu os cuidados para o tratamento em domicílio, tais como: autocateterismo, manobras de Vasalva e Credé, técnica de transferência da cama para a cadeira de rodas e vice-versa, com a ajuda de familiares. Prefere - banho na cadeira de rodas, realiza as atividades de toal ete e higiene sozinho. Sente necessidade de alguém para conversar. Diz-se inseguro em relação à alta hospitalar, mas que está tentando superar este medo.

\section{Avaliação}

"A senhora esuasalunas sabem o queeu queria e me ajudaram da melhor forma possível, eu confio no conhecimento e no apoio quea sra. me dá; essa parceria faz eu sentir muito grato a sra e as alunas. Elasforam boase principalmenteporque vejo que elas gostam dos paraplégicos; a parceria com a senhora me ajudou muito porque aprendi muitas coisas. As alunas sabem das coisas, a senhora tanto sabecuidar da gentecomo ensinar assuas alunas. Tem as alunas que conversam muito com a gente, dão a maior atenção, fazem o banho, dão orientação, dão força, esperança e, também, entusiasmo a gente". (C)

No dia 02/06/2000, ele recebeu alta hospitalar. Nos despedimos efetuando trocas de números de telefones e garantindo que ele poderia nos procurar sempre que houvesse necessidade.

PÉRICLES, 24 anos, solteiro, comerciário, evangélico praticante. É declassemédia, mora em Fortaleza com os pais e uma irmã, tem escolaridade de ensino fundamental incomple to. Admitido em 27/07/2000, após atropelamento. Apresenta TRM lombar, fratura de $L_{4}$ com fragmentos ósseos no canal e paraplegia flácida. Submetido à artrodese de coluna por via posterior. Está com 30 dias de internação hospitalar. A parceria efetuou-se através de nove encontros, o primeiro dos quais aconteceu no dia 27/08/2000, pela manhã, em uma conversainformal.

\section{Levantamento dos dados}

"Eu me sinto muito deprimido, assim com uma coisa ruim no peito, É uma dor muito grandenão poder maisandar não mexer mais as pernas. Às vezes quero me revoltar, é isso mesmo, estou revoltado, não sei porqueisso aconteceu comigo. Eu nunca fiz mal a ninguém. $A$ minha re volta é com o que aconteceu, um irresponsável me atropelou, foi embora nem mesocorreu". (A) 
"Eu não tenho muito que pedir... era muito bom setivessemaisenfermeira que gostasse de conversar. Elas também, são muito ocupadas eu penso que sim. M ais eu bem que queria saber tantas coisas: como, o que eu posso fazer, se eu ainda vou ter "vida com mulher", como vai ser quando eu estiver em casa. Eu não tenho ninguém para meajudar, vou ter queme cuidar sozinho, então eu preciso que a enfermeira me ensine as coisas que eu preciso aprender, como tomar banho". (B)

\section{D iagnósticos de enfermagem}

- Enfrentamento individual ineficaz relacionado à incerteza e à crise situacional, evidenciado pela verbalização da incapacidade de enfrentamento.

- Adaptação prejudicada relacionada ao estado de saúde que requer mudanças no estilo de vida, evidenciada pela demonstração de não aceitação da paraplegia.

- Angústia espiritual, relacionada a crenças e sistemas de valores desafiados, evidenciada pela verbalização de conflito interior.

- M obilidade física prejudicada relacionada a prejuízos neuromuscular e sensorioperceptivo, evidenciada pela paraplegia.

- Disfunção sexual relacionada às estruturas da função corporal alteradas pela lesão me dular, evidenciada pela ausência de ereção e verbalização da incapacidade sexual.

- Padrões de sexualidadealterados relacionados à alteração na estrutura funcional (ausência de sensibilidade nos M M II), evidenciados pela limitação física.

\section{Planejamento do cuidar/cuidado}

M etas- Atenção especial aos fatores de cuidado

Fator 4. Um relacionamento decuidar humano baseado na confiança e no esforço.

Fator 7. 0 ensino-aprendizagem transpessoal.
Fator 8. Ambiente de suporte, proteção e/ou ajustamento.

Fator 9. Gratificação das necessidades humanas de mobilização.

\section{Cuidados transpessoais}

- Encorajar o autocrescimento, permitindo aflorar os seus sentimentos de modo sensível.

- Favorecer, por meio da interação e do diálogo, a expressão dos sentimentos positivos enegativos.

- Estimular o uso de terapias opcionais de cuidado para promover a saúde, tais como: toque, abraços, sorrisos, massagens, oração e pensamento positivo.

- Dar suporte, através de aconselhamento sobre sexualidade.

- Deixar desabafar, falar da sua revolta.

- Promover uma educação individual, o ensino do autocateterismo intermitente.

- Oferecer cuidados para promover higiene, esvaziamento vesical, ajudar na alimentação, fazer e ensinar a mobilidade física no leito e mudança de decúbito.

- Propiciar contato com a parceira.

- Orientar cuidados de acordo com a solicitação do paciente.

- Falar individualmente sobre o tipo de lesão medular ocorrida e o que acontece com a função sexual.

- Orientar cuidados para evitar acidentes e constrangimentos durante 0 ato sexual.

- Ensinar cuidados relativos à higieneíntima.

- M anter a orientação sexual apósa alta, através de visitas domiciliares.

\section{Evolução}

0 pacienteapresenta um sentimento deraiva muito acentuado, em especial, quando se reportou ao acidente. Nota-se, também, uma grande esperança em Deus. Expressões detristeza e dor estavam sempre presentes no seu 
semblante. Queixa-se ao dizer que as enfermeiras não demonstram preocupação com os seus sentimentos. Apresenta depressão. Está ansioso com o resultado da cirurgia, e revoltado com a situação. Sente-se diferente, preocupado porque vai ficar desempregado; referequeseu mundo não émaiso mesmo. Aprendeu 0 autocateterismo e as manobras deValsalva e Credé. Senta no leito com ajuda.

\section{Avaliação}

"Ter alguém que cuide assim de mim, é como seela segurassea minha doença, fica mais leve. Vocês me deram perspectivas, uma coisa difícil deseter quando seéacometido pela paraplegia; a senhora me conhece e pode antecipar problemas e também a aluna meensinou muitascoisas. Eu me sinto seguro, sei que posso contar com a senhora ecom as alunas semprequeprecisar, inclusive já fiz isso várias vezes. A sra. éa primeira enfermeira quevem aqui ediz queestá preocupada comigo. Eu acho isso bom, muito bom mesmo". (C)

Em 22/09/2000, aconteceu o último encontro porque ele estava de alta hospitalar. Fomos para o pátio interno do hospital a pedido dele, enessemomento el evoltou a falar da sua disposição em tentar viver melhor. Reiteramos o desejo de ajudá-lo, que procuraríamos estar sempre disponíveis às suas necessidades. Revisamos nossos números tel efônicos. Abraçamo-nos emocionados ediscretas lágrimas surgiram nos seus olhos. No dia 10/10, fizemos uma ligação telefônica para ele, pois estávamos preocupadas. Conversamos demoradamente e sentimos uma discreta mudança na sua voz: el e demonstrava al egria.

PEIXOTO, 19 anos, solteiro, pintor de paredes, católico. É declassemédia, mora em Caucaia, com os pais e seus irmãos. Possui escolaridadede ensino fundamental incompleto. Admi- tido em 15/09/2000, após agressão por projé til de arma de fogo. Apresenta TRM torácico, com paraplegia, nível sensitivo $T_{10} . N$ ão foi submetido à cirurgia porque, em seu caso, não havia indicação. Estáhospitalizado há 20 dias. A parceria realizou-se em dez encontros. 0 primeiro aconteceu no dia 05/10/2000, pela manhã.

\section{Levantamento dos dados}

"A gente se sente mal... quando a gente pensa ficar numa cadeira de rodas, deficiente não poder ir para um canto, fazer as coisas que a gente gosta eu me sinto mal por dentro, mas, eu sinceramente eu acredito muito que, um dia vou andar. 0 que peço muito a Deus é que um dia eu me recuperee possa viver minha vida de novo, minha preocupação é em relação a namoradas, não poder ter um relacionamento como tinha antes, não poder maister filhos, essas coisas assim, a gente pensa muito nisso. Eu penso muito nisso, uma relação com uma mulher quevai ser diferenteagora, penso também como vai ser a convivência em casa, quando a gente passar ever as pessoas brincando, jogando bola, se divertindo, a gente não poder mais fazer aquilo, a gente vai sentir um pouco". (A)

"Eu acho que as enfermeiras deviam ser umas pessoas que chegassem pra gente e dissessem: Como vai! Sentasse na cadeira e conversasse, desse uma palavra... que é pra ver sea gente melhora, que desseuma palavra amiga, prá gente ficar melhor, porque tem horas que a gente tá muito ruim, por dentro né... que nem a gente pensa porqueaconteceu isso comigo eserá que eu nunca mais vou andar. Eu queria que, nessa hora, ela desse uma palavra de bondade dizendo assim: tenha calma que as coisas vão melhorar. Vocênão podeandar, mas eu vou Iheajudar". (B) 


\section{Diagnósticos de enfermagem}

- Disfunção sexual relacionada à estrutura da função corporal alterada pela lesão medular, evidenciada pela ausência de ereção e verbalização da incapacidade sexual.

- Padrões de sexualidadealterados relacionados à alteração na estrutura funcional (ausência de sensibilidade nos M M II), evidenciados pela limitação física.

- Angústia espiritual relacionada a crenças e sistemas deval ores desafiados, evidenciados pela verbalização de conflito interior.

- Distúrbio da imagem corporal relacionado à perda da função em parte do corpo (paraplegia), evidenciado pela verbalização de percepções que refletem uma visão alterada do próprio corpo na aparência, estrutura e função.

\section{Planejamento do cuidar/cuidado}

M etas- Atenção especial aos fatores de cuidado

Fator 4. Estabelecimento de um relacionamento de ajuda e confiança.

Fator 7. 0 ensino-aprendizagem transpessoal.

Fator 8. Ambiente de suporte, proteção e/ou ajustamento.

Fator 9. Gratificação das necessidades humanas de sexualidade e Necessidade de buscar 0 crescimento.

\section{Cuidados transpessoais}

- Favorecer a formação da relação pessoa/pessoa por meio da interação e do diálogo.

- Aumentar a sensibilidade do paciente, encorajando 0 autocrescimento, permitindo que aflore seus sentimentos de modo positivo.

- Oferecer suporte emocional efazer aconseIhamento sobre sexualidade, e reprodução da pessoa paraplégica.

- O uvir empaticamente o paciente, favorecer a expressão de sentimentos.
- Promover o cuidado humano baseado na confiança e esforço.

- Orientar cuidados relacionados ao retorno da atividade sexual deacordo com a solicitação do paciente.

- Falar, individualmente, sobrea sua lesão medular ea conseqüência na sua sexual idade.

- Ensinar cuidados quese deve ter para evitar acidentes durante 0 ato sexual.

- Promover uma educação individual sobreo ensino do autocateterismo intermitente. - Oferecer cuidados para promover higiene, esvaziamento vesical, ajudar na alimentação, fazer eensinar a mobilidade física no leito e mudança de decúbito.

\section{Evolução}

O paciente está deprimido e preocupado em relação à falta de informação sobre a sexualidade e a reprodução humana após a paraplegia, assim como, a perda do convívio social. Está com medo de não mais poder ter filhos, e de não ter uma vida sexual satisfatória. Aprendeu a técnica de transferência da cadeira de rodas para a cama e vice-versa. M ostra-se animado sobre muitos aspectos da sua condição de paraplégico, no entanto, continuou demonstrando preocupação sobre as questões da sexualidade, apesar de ter sido esclarecido por nós. Aprendeu o autocateterismo, aceitou a ajuda das professoras e das alunas para aprender os cuidados que utilizará no domicílio. De monstra entusiasmo, pois recebeu alta hospitalar e aguarda os familiares para a sua saída.

\section{Avaliação}

"Para mim o suporte emocional oferecido pela senhora e suas alunas foi baseado na honestidade e simpatia; a sensação de ser cuidado por alguém que se preocupa comigo e ter alguém com que contar me deu esperanças para o futuro. 0 benefício é que eu estou me sentindo 
uma pessoa amada e cuidada. Pela manhã, eu sou cuidado pela aluna epela sra.. Aí sim, a menina ea sra. conversam comigo... eu gosto, poiséuma alegria só aqui na enfermaria. Tudo que vocês fazem é com alegria, a gente vendo isso se al egra também". (C)

Nosso último encontro no hospital aconteceu no dia $27 / 10 / 2000$, pois ele estava de alta hospitalar prevista para o dia seguinte. Revisamos alguns aspectos da parceria e reforçamos o compromisso em ajudá-lo. Ele mostrou-se mais uma vez interessado em mantermos contatos.

POLICARPO, 20 anos, solteiro, vendedor, católico não-praticante. Tem escolaridade equivalenteao ensino fundamental incompleto. $\hat{E}$ declasse média baixa, mora em Fortal eza com os pais e dois irmãos. Admitido em 10/10/ 2000, com TRM torácico de $\mathrm{T}_{4}$ e $\mathrm{T}_{5}$ com paraplegia flácida, ocasionada por agressão por projétil de arma de fogo. $\mathrm{N}$ ão foi submetido à cirurgia porque não há indicação cirúrgica. Encontra-se hospitalizado há 13 dias. Com Policarpo, a parceria realizou-se em dez encontros. O primeiro aconteceu no dia 23/10/ 2000 , pela manhã. Os demais encontros aconteceram nos dias subseqüentes à internação.

\section{Levantamento dos dados}

"Sinto-me péssimo... (baixa a cabeça) imagine uma pessoa nova como eu, saber quenunca mais vai andar... É loucura... às vezes, fico aqui sozinho de noite pensando, eu penso como vai ser minha vida deagora em diante. Aí... eu choro... não deixo os outros verem, é de tristeza que eu choro.Eu só tenho 20 anos fiz no mês passado. Será que isso é castigo? Por que Deus fez isso comigo? Eu me sinto aleijado. Não sou mais homem. Sabe as meninas mechamam debonitinho.Agora não sou mais. Até minha namorada não mequer mais. Isso tudo me deixa muito triste, preocupado com minha vida, agora e depois, meu emprego. Ter que fazer tudo com ajuda dos outros isso é horrível. Sabe o queeu maisqueria era andar outra vez. Será que existe milagre?" (A)

"Eu não tenho queixa nenhuma, elascuidam bem, mas seel as conversassem mais, se dessem mais atenção para a gente ia ser melhor. Tem delas queficam longe da gente, só vem aqui nas horas de passar a sonda. Por exemplo, elas podiam todo dia conversar um pouco, perguntar o que eu estou sentindo... se eu preciso de alguma coisa... O lha não é "fuxico" eu só estou dizendo como me sinto. Uma coisa que as enfermeiras podiam fazer era tirar todo dia uma horinha para conversar com a gente, saber mais das nossas vidas... é pedir muito? Denoite, a tristeza émaior, nessa hora, elas bem podiam dar atenção perguntando como a gente está". (B)

\section{Diagnósticos de enfermagem}

- Distúrbio da imagem corporal relacionado à perda da função em parte do corpo (paraplegia), evidenciado pela verbalização de percepções que refletem uma visão alterada do próprio corpo na aparência, estrutura e função.

- M obilidade física prejudicada relacionada a prejuízo neuromuscular, evidenciada pela paraplegia.

- Disfunção sexual relacionada às estruturas da função corporal alteradas pela lesão medular, evidenciada pela ausência de ereção e verbalização da incapacidade sexual.

- Padrões de sexualidadealterados relacionados à alteração na estrutura funcional (ausência de sensibilidade nos M M II), evidenciada pela limitação física.

- Angústia espiritual relacionada a crenças e sistemas de valores desafiados, evidenciada pela verbalização de conflito interior. 


\section{Planejamento do cuidar/cuidado}

M etas- Atenção especial aosfatores de cuidado

Fator 2. Instalação da fé-esperança.

Fator 7. 0 ensino-aprendizagem transpessoal.

Fator 8. Ambiente de suporte, proteção e/ou ajustamento.

Fator 9. Gratificação das necessidades humanas de sexualidade e necessidade de busca e crescimento.

\section{Cuidados transpessoais}

- Falar sobre a lesão medular e repercussões na função sexual.

- Favorecer a formação da relação pessoa/pessoa por meio da interação e do diálogo.

- Permitir o afloramento dos seus sentimentos de modo sensível.

- Fazer o paciente reconhecer sua capacidade de manter o relacionamento afetivo esexual.

- Estimular o autocrescimento.

- Utilizar terapias alternativas tais como: toque, abraços, sorrisos, massagens, oração e pensamento positivo.

- Aumentar a sensibilidade do paciente, encorajando-o a falar dos seus sentimentos.

- Oferecer suporte emocional e fazer aconseIhamento sobresexualidadee reprodução da pessoa paraplégica.

- Orientar cuidados para favorecer o reinicio das atividades sexuais.

- Ouvir o paciente empaticamente.

- Promover uma educação individual sobreo ensino do autocateterismo intermitente.

- Oferecer cuidados para promover higienee esvaziamento vesical.

- Ajudar na alimentação.

- Fazer eensinar a mobilidadefísica no leito e mudança de decúbito.

\section{Evolução}

A parentemente tranqüilo, diz-se orientado sobre a sexualidade após a paraplegia, mas continua com medo denão poder ter uma atividadesexual satisfatória. Foram ensinadas as técnicas de transferência da cama para a cadeira derodas evice-versa, tendo feito adequadamente com a ajuda dos familiares. A prendeu 0 autocateterismo, as manobras deVasalva e Credé. Sente-se esclarecido sobre os cuidados para a continuidade do tratamento no domicílio. Está animado com a possibilidade de alta hospitalar próxima. Aguarda a chegada da mãe para as providências sobre sua saída.

\section{Avaliação}

"Eu reconheço quea ajuda oferecida pela senhora esuas alunas foi baseada na honestidade e simpatia; foi muito bom ser cuidado por alguém que se preocupa comigo, que me deu outras maneiras de encarar o futuro. 0 ben efício équeeu estou mesentindo uma pessoa amada ecuidada. Pela manhã, eu sou cuidado pela aluna e pela sra. No começo sei que fui chato com a menina e com a sra. Eu gostei desse cuidado que foi feito em mim. Fiquei alegre, algumasvezes, aqui na enfermaria". (C)

Nosso último encontro no hospital aconteceu no dia 28/10/2000, pois ele sairia dealta hospitalar no dia seguinte. Revisamos al guns aspectos da parceria e reforçamos o compromisso em ajudá-lo. Ele mostrou-se mais uma vez interessado em mantermos contatos. Policarpo nunca fez nenhum contato tel efônico conosco. Fizemos várias tentativas de comunicação mas todas sem sucesso. Em novembro de2001, após contato tel efônico com sua mãe, recebemos a notícia de que ele havia falecido no dia 20 denovembro. Estefato nos 
deixou muito tristes etambém frustradas, pois com este pacientea parceria não obteve êxito.

PÁDUA, 41 anos, casado, policial militar, católico praticante. É de classe média, mora em Fortaleza com a esposa e quatro filhos. Tem escolaridade equivalente ao ensino médio completo. Internado em 20/02/01, apresenta traumatismo raquimedular torácico, com paraplegia nível sensitivo $\mathrm{T}_{4}$ e $\mathrm{T}_{5^{\prime}}$, ocasionado por acidente de moto. Realizou artrodese de coluna torácica, e encontra-se hospitalizado há 33 dias. A parceria com Pádua efetuou-se em dez encontros. 0 primeiro aconteceu no dia 05/04/2001, pela manhã.

\section{Levantamento dos dados}

"Eu entrego a Deus! A minha vontade é andar, masou Deus querendo ou não, claro que ele quer justamente, que ele quer isso, queeu vou andar, tenho muita fénisso, tenho muita fé em Deus! M eus sentimentos éque vou voltar a andar. N ão me sinto tristegraças a Deus, com Ele consigo o quequero. Ah! Saudadeeu tenho do meu filho desetemeses, masjá estou indo para casa graçasa D eus, né... Sei quetenho um problema decoluna, mais ele dissequetenho uma chanceboa, $10 \%$ dechanceéboa, se eu sentir algum movimento é ótimo, para voltar a andar novamente". (A)

"Ah! Eu gostaria que elas me dessem banho, que algumas delas não dão banho na gente, não são todas, masisso era bom, se elas pudessem dar banho no paciente, assim como a Sra. e suas alunas fazem. Para eu mesentir melhor, eu gostaria que elas conversassem com o paciente, a conversa sempre é melhor para o paciente. U ma boa enfermeira é aquela que chega pra gentepara conversar, masnem todas fazem isso. Elas não conversam sobre re ligião e sexo, eu bem que gostaria". (B)

\section{Diagnósticos de enfermagem}

- Déficit no autocuidado para banho/higiene relacionado a prejuízo neuromuscular evidenciado pela incapacidade de lavar-se.

- M obilidade física prejudicada, relacionada a prejuízos neuromusculares e sensorioperceptivos, evidenciada pela paraplegia.

- Disfunção sexual relacionada às estruturas da função corporal alteradas pela lesão medular, evidenciada pela ausência de ereção e verbalização da incapacidade sexual.

- Padrões de sexualidadealterados relacionados à alteração na estrutura funcional (ausência de sensibilidade nos M M II), evidenciados pela limitação física.

- Angústia espiritual relacionada a crenças e sistemas de valores desafiados, evidenciada pela verbalização de conflito interior.

\section{Planejamento do cuidar/cuidado}

M etas - Atenção especial aos fatores decuidado

Fator 2. Instalação da fé esperança.

Fator 7. 0 ensino-aprendizagem transpessoal.

Fator 8. Ambiente de suporte, proteção e/ou ajustamento.

Fator 9. Gratificação das necessidades humanas de sexualidadee de ordem superior (interpessoal e transpessoal), necessidade de buscar o crescimento.

\section{Cuidados transpessoais}

- Aumentar a sensibilidade do paciente, encorajando o autocrescimento.

- Promover o cuidado humano baseado na confiança e esforço.

- Estimular a socialização através do contato com amigos e familiares.

- Favorecer a formação da relação pessoa/pessoa por meio da interação e do diálogo.

- Fazer o paciente reconhecer sua capacidade demanter o relacionamento afetivo e sexual. 
- Oportunizar a expressão de sentimentos acerca das crenças e valores.

- Discutir formas alternativas para dar continuidade a sua participação no ritos religioSOS.

- Estimular a participação no autocuidado (banho, higiene oral).

- Promover uma educação individual sobre o ensino do autocateterismo intermitente.

- Oferecer eensinar os cuidados para promover higiene e esvaziamento vesical.

- Ajudar na alimentação.

\section{Evolução}

O paciente está preocupado com a dificuldade para realizar sua higiene corporal e a falta de informação sobre a sexualidade. Informa medo de não poder voltar a ter uma atividadesexual satisfatória. Aprendeu astécnicas de transferência da cama para a cadeira e viceversa eas pratica com freqüência. Demonstra interesse em tudo que lhe é ensinado. Diz-se esclarecido sobre a paraplegia e sobre os cuidados necessários para a continuidade do tratamento no domicílio. 0 paciente sente-se ajudado, verbaliza seusmedoseanseios. Aprendeu 0 autocateterismo, executa manobras de Vasalva e Credé. Realiza sua própria higiene na cadei ra de rodas com a ajuda do acompanhante.

\section{Avaliação}

"Eu não sei nem mesmo como agradecer tudo quea senhora e suas alunasfizeram por mim; eu sinto que vocês se preocupam verdadeiramente comigo, até me deixam menos aprensivo, pois sei agora que tenho com quem contar na hora de aflição que eu estou me sentindo uma pessoa muito bem cuidada. A sra. e suas alunas são os anjos queD eus colocou nos nossos caminhos". (C)
Nosso último encontro no hospital aconteceu no dia 28/04/2001. Ele recebeu alta hospitalar e na ocasião, revisamos alguns aspectos da parceria e reforçamos o compromisso em ajudá-lo. M ostrou-se mais uma vez interessado em mantermos contatos. 0 último foi no dia 11 de novembro de 2001, ocasião em que fomos entrevistados para o "programa quadro de saúde" da TV Diário do Nordeste, elhe entregamos o livro: Viva Bem com a sua lesão medular - manual deorientação, deCarvalho e Damasceno (2001).

\section{ANÁLISE DOSDADOS}

Como vimos páginas atrás os discursos obtidos foram o ponto de partida para a aplicação da teoria. Deles também emergiram categorias cujas análises estão discutidas a seguir:

\section{Categoria 1. Ser paraplégico significa vivenciar uma perda pontilhada de um misto de sentimentos}

Os estudados dizem que, com a paraplegia, perdem a liberdade de ir e vir e a sexualidade, ficando dependentes. É, portanto, vivenciar um complexo processo de transformação da vida, permeado por sentimentos diversos. A perda cria uma desarmonia na existência da pessoa, que é expressada por sentimentos de tristeza, mágoa, inconformismo, isolamento, angústia, choro, dor esofrimento emocional. 0 sofrimento profundo altera o sentimento de si próprio, surgindo o questionamento: eu não estou igual ao que eu era.

Os pontos fundamentais no modelo transpessoal de Watson (1999) são a perda e o cuidado. A perda gera uma desarmonia nas três esferas da pessoa: a mente, o corpo eo espírito, por isso demanda cuidados que considerem o mundo emocional esubjetivo. Sobre essa situação, Vidor (2000) diz eu queria dormir eacordar na hora quea cura tivesse sido descoberta e pronto. Infelizmente, não tenho esse poder.

Benson (1996) afirma que as doenças de 
uma maneira geral, assim como as perdas, muitas vezes fazem com queas pessoas se voltem para Deus. São incontáveis as situações em que o desespero diante da doença e da perda éprelúdio para a recuperação da fé. Por sua vez Glynn (1997) defende a crença religiosa como condição para a felicidade e bem estar psicológico no âmbito geral.

Na paraplegia a sexualidadetambém éafetada trazendo sérios problemas de ajustamento e sentimento de inferioridade. Compete à enfermeira procurar conhecer e orientar os paraplégicos acerca dos problemas sexuais conseqüentes à lesão medular, desmistificar o que existe sobre paraplegia e sexualidade, bem como discutir a respeito das opções para dar e receber prazer sexual.

\section{Categoria 2. Cuidados desejados privilegiam 0 atendimento das necessidades biológicas, espirituais e emocionais}

A esta indagação, os pacientes se dizem desejosos de cuidados voltados para o ensinoaprendizagem de procedimentos técnicos necessários ao cotidiano. Por outro lado, privilegiam os cuidados baseados em atitudes e valores ao expressarem: -uma coisa que as enfermeiras podiam fazer era tirar todo dia uma horinha para conversar com a gente, saber das nossas vidas. Tal posicionamento está de acordo com Watson (1988) ao mostrar que o foco central da enfermagem está no fato de que o cuidado se deriva de uma perspectiva humanística, combinada com uma base de conhecimentos científicos. No entanto, valoriza o cuidado humano afirmando que este inclui atenção individual, carinho e amor.

\section{Categoria 3. A parceria é uma estratégia de cuidado que atende sobretudo as necessidades emocionais e espirituais}

Os discursos dos paraplégicos que foram alvos da aplicação da teoria apontam quea par- ceria proporcionou 0 atendimento das suas necessidades emocionaise espirituais deixando-os mais seguros para enfrentar a sua nova condição. M aisuma vez, fica demonstrado que a teoria de Watson (1988), ao valorizar o cuidado humano, oferece às enfermeiras a oportunidade para refletirem sobreas possibilidades de mudanças no cenário de cuidados aos paraplégicos.

\section{CONSIDERAÇÕES FINAIS}

A Teoria do Cuidado Humano é baseada na crença de que, quando uma enfermeira eum paciente estão juntos, eles criam a possibilidade de en contrar uma significação dentro da experiência por elesvivenciada. Como Watson (1999) explica, a arte do cuidar em enfermagem começa quando a enfermeira, com o objetivo de ajudar o outro através de um sentimento de cuidado e atenção, expressa esse sentimento com atitudes concretas. Ela vai mais além, lembrando que essa noção de cuidar/cuidado intersubjetivo se opõe aos modelos "de cuidar para" e"cuidar de". Essa idéia foi fundamental para a prática do modelo proposto. Na implementação realizada, as docentes, alunas e pacientes foram considerados participantes iguaisnas relações decuidar em parceria ecada participanteteveo poder igual de negociar e renegociar os pensamentos do relacionamento.

Assim sendo, tornou-se muito aparente que o relacionamento intersubjetivo e transpessoal, formado durante a aplicação do modelo de parceria no cuidar/cuidado, deu condições para encontrarem significadosna forma de compreender as implicações da paraplegia para o cotidiano da pessoa acometida.

Os fatores de cuidado preconizados por Watson (1979) refletem princípios humanísticos e científicos, envolvidos na prática da enfermagem, que se baseiam na teoria do cuidado humano. A utilização dos fatores decuidado é de fundamental importância para documentar, mutuamente, planos e metas; a en- 
fermeira indica qual fator deve direcionar as interações presentes e futuras.

A parceria gerou satisfação para os envolvidos eestimulou a realização de práticasinovadoras, tais como: cuidados alternativos do tipo toque e abraços, o incentivo ao pensamento positivo, contato visual, atitudecalma, timbre de voz agradável e a impressão geral de gostar do que faz e de sentir prazer em estar com os paraplégicos. Tudo isso foi referido quando da avaliação realizada anteriormente.

Um ponto forte foi o crescimento pessoal, propiciado aos pacientes e a nós, traduzido por relacionamentos interpessoais mais significativos, como a ajuda - confiança e ainda os pacientes terem referido sentirem-selivres para serem honestos com eles mesmos e conosco. Nesse sentido a confiança foi muito valorizada pelos pacientes 0 que foi detectado nas visitas domiciliares.

M erece ser destacado que essa experiência ofereceu especial oportunidade para usar a base da enfermagem no desenvolvimento de uma filosofia de cuidar e, assim, tornar as enfermeiras e alunas mais sensíveis aos problemas dos paraplégicos. Desse modo, aplicar o M odelo deCuidado Transpessoal nessa clientela foi uma maneira de estender a teoria à prática e ofereceu oportunidade de crescimento eautonomia da enfermagem no cenário hospitalar.

Trabalhar com uma teoria deenfermagem não foi tão difícil como tem sido apontado pelas enfermeiras. Ao contrário, foi um exercício necessário para melhor entender a aplicabilidade da teoria de Jean Watson. No entanto, a implementação do modelo de cuidado transpessoal foi possível graças ao apoio dos pacientes e das alunas do quinto semestre do Curso de Graduação em Enfermagem. Apesar de não haver envolvido a família diretamente, a parceria também a beneficiou, através do ensino-aprendizagem dos cuidados para a continuidade do tratamento no domicilio.

O que foi aqui relatado indica que éviável se pensar numa enfermagem fundamentada em teorias e conceitos, desde que seus pressupostos sejam compreendidos. Cabelembrar que a maior dificuldade encontrada foi o descompasso entrea objetividade do método cientifico e a subjetividade da parceria utilizada para promover o cuidado transpessoal. Essefato pode ser sanado a partir do momento que a enfermeira consiga equacionar os aspectos que envolvem essa questão. Da aplicação da teoria de Watson resultaram aspectos enriquecedores, no entanto ela não está isenta de dificuldades, em especial quando o mundo da enfermeira não é compatível com as crenças ou a fé do paciente.

Como aspectos negativos, é importante mostrar que não houve oportunidade de engajamento das enfermeiras de serviço, por se tratar de uma experiência realizada durante a elaboração de uma tese de doutorado. M esmo assim, defendemos que é necessário articular mecanismos para despertar o entusiasmo delasa estenovo olhar no cuidado com o paciente paraplégico, visto que não podemos pensar em aplicar teorias deenfermagem na prática sem o envolvimento das enfermeiras de serviço.

O modelo decuidado aplicado teveum significado importante para nós. Foi um momento de descobrimento, de exercício da intersubjetividade, pois, na medida em que interagíamos com os pacientes, aprendíamos, cada vez mais, a reconhecêlos como seres humanos, eassim, refletíamos sobresuas maneiras de viver, ser e agir ejuntos procurávamos compreender o significado do cuidado ao paraplégico através de nossos diálogos.

Para os alunos, acreditamos que, cuidar de pessoas paraplégicas com baseem um modelo conceitual, em especial uma teoria humanística, foi um exercício rico que possibilitou compreender melhor as crenças acerca da pessoa, da saúde, do ambiente e do cuidado. Assim como, sederam conta da importância do planejamento do cuidado com a pessoa paraplé gica, para prestarem cuidados mais humanísticos e de melhor qualidade. Notamos ainda, 
que os alunos tomaram consciência da necessidade de desenvolver um modo de pensamento lógico erigoroso chamado processo de enfermagem, para planejarem as intervenções para essa clientela.

Por fim, concordamoscom Phaneuf (1996) quando diz que aplicar uma teoria éuma ferramenta desistematização e de humanização dos cuidados, tornando-se assim, um instrumento de valorização profissional. Ofertar cuidados, pautados em uma teoria de enfermagem, permite a enfermeira trabalhar de maneira mais responsável e verdadeiramente profissional.

\section{REFERENCIAS BIBLIOGRÁFICAS}

ALFARO-LE FEVRE, R. (2000). Aplicação do processo de enfermagem - um guia passo a passo. Porto Alegre: ArtM ED Editora.

BENSON, H. (1996). Timeless Healing. New York: Simon e Schuster.

BRASIL.CONSELH O NACIONAL DESAÚDE. (1997). Resolução 196/96. Brasília.

CARRARO, T.E. (2001). Sobre teorias e marco conceitual: sua influência na metodologia da assistência. In: Westphalen, M .E.A; Carraro, T.E. $M$ etodo- logias para a assistência de enfermagem: teorizações, modelos e subsídios para a prática. Goiânia: AB Editora.

CARVALHO, Z.M .F.; DAM ASCEN O, M .M.C. (2001). Viva bem com a sua lesão medular: manual de orientação. Fortaleza: DENF/UFC.

CHIN N, P.L., KRAM ER, M. K. (1995). Theory and nursing: a systematic approach. St. Louis: M osbyYear Book.

GLYNN , P. (1997). God the Evidence: thereconciliation of faith an reason in a postsecular world. New York: Prima Publishing.
HICKM AN , J.S. (2000). Introdução à teoria da enfermagem. In: George, J.B. Teorias de Enfermagem: osfundamentos à prática profissional. Porto Alegre: Artes M édicas Sul.

IYER, P.W.; TAPTICH , B.I .; BERN OCCHI-LOSEY, D. (1993). Processo e diagnóstico de enfermagem. Porto Alegre: Artes M édicas).

MACH AD O, W.C.A (2002). Tempo, espaço e movimento: o (d)eficientefísico, a reabilitação eo desafio de conviver com o corpo partido. Rio de Janeiro: Papel Virtual.

NORTH AMERICAN NURSING DIAGNOSISASSOCIATION (2000). Diagnósticos deEnfermagem da Nanda - definições e classificação 1999-2000. Porto Alegre: Artes M édicas.

PADULA, M.C.P. (1998). Caracterização dos déficits de autocuidado universal da pessoa com lesão me dular. São Paulo: Dissertação de M estrado. Universidade Federal de São Paulo.

PHANEU F, M . (1996). La planification des soins: um système integré et personalizé. Montreal: Les Editions de la Chenelière.

SH ROEDER, C.; M AEVE, M. K. (1992). Nursing care partnerships at the Denver Nursing Project in human caring: an apllication and extension of cairns theory in pratice. Advances in N ursing Science, 15, 25-38.

TOBAR, F.; YALOUR, M .R. (2001). Como fazer teses em saúde pública. Rio de Janeiro: Editora Fiocruz.

VIDOR, G. (2000). Sem limites. São Paulo: Editora Monole.

W ATSO N, J. (1985). Nursing: human science and human care, atheory of nursing. New York: $N$ ational League for Nursing.

WATSON , J. (1988). Nursing: human scienceand human care, a theory of nursing. New York: National League for Nursing.

WATSO N, J. (1999). Nursing: human scienceand human care, a theory of nursing. N ew York: National League for Nursing.

WATSO N, J. (1979). Nursing: thephilosophy and science of caring. Boston: Litle Brown. 